Provided for non-commercial research and education use. Not for reproduction, distribution or commercial use.

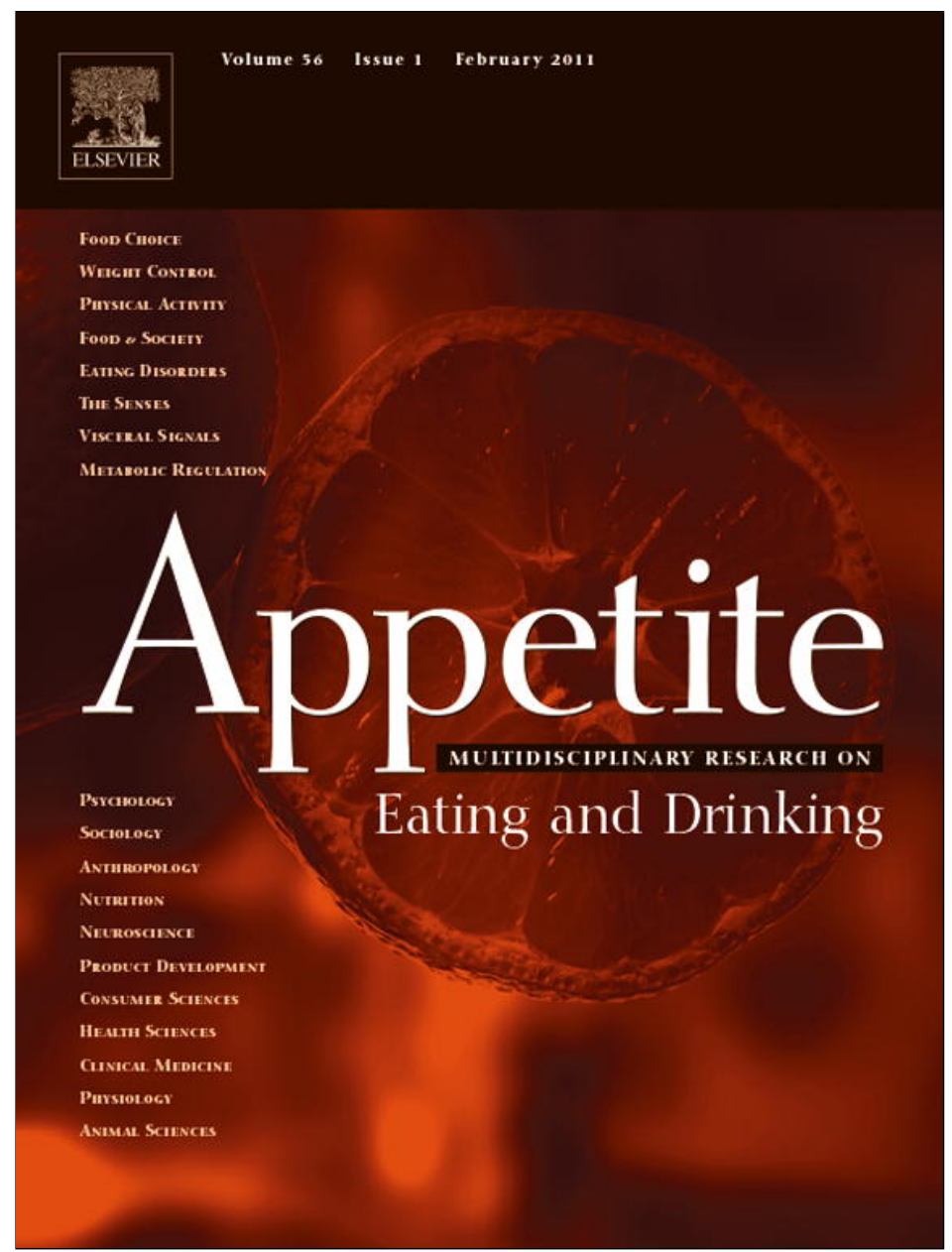

This article appeared in a journal published by Elsevier. The attached copy is furnished to the author for internal non-commercial research and education use, including for instruction at the authors institution and sharing with colleagues.

Other uses, including reproduction and distribution, or selling or licensing copies, or posting to personal, institutional or third party websites are prohibited.

In most cases authors are permitted to post their version of the article (e.g. in Word or Tex form) to their personal website or institutional repository. Authors requiring further information regarding Elsevier's archiving and manuscript policies are encouraged to visit:

http://www.elsevier.com/copyright 
Research report

\title{
Finishing the family meal. The interactional organisation of satiety
}

\author{
Eric Laurier ${ }^{\mathrm{a}, *}$, Sally Wiggins ${ }^{\mathrm{b}}$ \\ ${ }^{a}$ School of GeoSciences, University of Edinburgh, Institute of Geography, Drummond Street, Edinburgh EH8 9XP, United Kingdom \\ ${ }^{\mathrm{b}}$ School of Psychological Sciences and Health, University of Strathclyde, Graham Hills Building, 40 George Street, Glasgow G1 1QE, United Kingdom
}

\section{A R T I C L E I N F O}

\section{Article history:}

Received 27 March 2009

Received in revised form 19 May 2010

Accepted 11 November 2010

Available online 21 November 2010

\section{Keywords:}

Mealtimes

Family

Satiety

Completion

Interaction

Conversation analysis

\begin{abstract}
A B S T R A C T
This paper provides an extended review of psychological, sociological and interactional research on mealtimes and satiety (fullness), arguing for a focus on how fullness and finishing a meal is interactionally achieved. Drawing on three specimen data fragments from contrasting family settings, routinely used resources for pursuing completion and expressing satiety are described. We show how checks on completion are tailored to children according to their age, the intimate knowledge family members have of one another and attuned to contingencies, such as, whether there is a further course to be offered. Equally, that in teaching children how to eat together with others, the family also transmits and transforms all manner of other eating practices such as how to comply, or not, with requests to finish. A central aim of the article is to complement the many studies of satiety that have explained its physiological aspects by providing the familial logics that are expressed in bringing the meal to a close. We offer a suggestive analysis, based on conversation analytic principles, to illustrate our argument and to provide a starting point for further work in this field. Where bodies of work have previously used mealtimes as a convenient setting for accessing other social practices, this article turns its focus back toward the tasks of dining together.
\end{abstract}

(c) 2010 Elsevier Ltd. All rights reserved.

\section{Introduction}

One method we have, in a time of plenty, for establishing whether any meal is finished or not is when all of those eating are full. Surely all that we require to know of one another, to end any meal, is to ask and, then, receive a statement as to whether we are full or not. What studying family meals in natural settings brings to light is the fact that even though a family member may claim they are full, parents and siblings can respond routinely that they are not, or have not finished or ask them whether they might want some dessert. The satisfaction of appetites and the statement of satiety turn out to be woven through with a variety of other mealtime activities.

In this introduction, we consider three areas of research that demonstrate the interdisciplinary nature and importance of this topic - finishing a meal - for eating research: psychology, sociology and interactional research. The latter work brings together concerns from the first two, and neatly leads into our preliminary work in this topic. This rather extended review of the literature is necessary, we argue, to demonstrate the complexity of the issue of fullness and finishing a meal. Our point is to demonstrate the need for an analysis of family mealtimes as a way to fully integrate

\footnotetext{
* Corresponding author.

E-mail addresses: eric.laurier@ed.ac.uk (E. Laurier), sally.wiggins@strath.ac.uk (S. Wiggins)
}

psychological, sociological and interactional perspectives on fullness and appetite.

\section{Psychology: Satiety and parental feeding practices}

Within psychological research on eating, there is a strong sense of hunger, satiety and appetite as being primarily physiological concepts (Friedman, Ulrich, \& Mattes, 1999; Raben, Tagliabue, \& Astrup, 1995), though attempts are being made to close the gap between physiological and psychological measures (Hetherington, 2002). Satiety, in this sense, is measurable and individualised. Much of this work takes place in laboratory settings, measuring both subjective ratings of satiety as well as the precise quantities of food eaten. For instance, participants consume 'meals' in a laboratory where they are provided with various foods and allowed to eat until they feel sated. Recurring evidence in this field points to the notion of sensory-specific satiety, where the palatability, taste and pleasure derived from one food decreases as more of this food is consumed (Hetherington \& Rolls, 1996; Rolls, Rolls, Rowe, \& Sweeney, 1981). This has implications for the quantity and type of food eaten; one may reach satiety for a particular food before satiety is reached for a whole meal (Hetherington, 1996).

Being full, or not, thus appears from this psycho-physiological perspective to be strongly related to the variety of foods that we eat. If we eat a bland diet or meal, we will quickly feel 'full'; the opposite is found when we eat a more varied diet (Hetherington, 
Foster, Newman, Anderson, \& Norton, 2006). Research in this area has also considered the context within which food is eaten, with social facilitation increasing our likelihood of eating more (Hetherington, Anderson, Norton, \& Newson, 2006; Rozin, 1990), as well as possible gender differences (Zylan, 1996). Such research still relies heavily on laboratory conditions, however, which create an artificial environment devoid of the complexity of social or familial obligations. Work that aims to provide a more comprehensive account of hunger and fullness through in-depth participant reports still assumes an individualistic model of satiety (Murray \& Vickers, 2009). Moreover, this work also comes with a warning that eating with others can have undesirable implications for those wishing to lose or manage their weight (Hetherington, Anderson, et al., 2006), and yet such conditions form the basis of the majority of our eating practices.

A further area of research within psychology considers the impact of parenting styles on child feeding practices (Farrow, Galloway, \& Fraser, 2009), often driven by a concern with childhood obesity or weight issues (Blissett \& Haycraft, 2008; Carper, Fisher, \& Birch, 2000; Faith, Scanlon, Birch, Francis, \& Sherry, 2004; Wardle, Sanderson, Guthrie, Rapoport, \& Plomin, 2002). The parenting styles or strategies typically examined include a range of practices, from encouraging children to finish their food, to controlling the type and amount of food that they eat (Bourcier, Bowen, Meischke, \& Moinpour, 2003; Hendy, WIlliams, Camise, Eckman, \& Hedemann, 2009; Sleddens, Kremers, De Vries, \& Thijs, 2010). This literature also points to a distinction between parenting 'styles' (i.e. the attitudes and beliefs of parents) and parenting 'practices' (behavioural strategies that are responsive to particular situations) (Hennessy, Hughes, Goldberg, Hyatt, \& Economos, 2010). As Ogden and colleagues have noted, however, there is some confusion in the literature as to whether stricter parental control results in healthy or unhealthy eating practices in children (Ogden, Reynolds, \& Smith, 2006). The issue may lie, they argue, in a difference between 'overt' parental behaviours (such as those of which the child is likely to be aware, e.g. telling the child to eat more or less food) and 'covert' behaviours (of which the child is likely to be unaware, such as avoiding bringing sweet foods into the home). The authors conclude that "parental control may be more complex than previously assumed" and that there might be a more subtle "micro-management" of the environment in which children eat and live (Ogden et al., 2006, p. 105). That said, the way in which such 'control' is examined is overwhelmingly through questionnaire-style studies; little research actually examines eating practices in situ.

The focus on parenting styles is narrowed further to a consideration of maternal feeding practices in some areas of the literature (Kroller \& Warschburger, 2008); here, the underlying assumption is that eating is a gendered practice and that women are the primary caregivers in this domain. Again, questionnaires prevail as the main research method, with scale items such as "do you allow your child to eat between meals?" (Tiggemann \& Lowes, 2002), though some research utilises qualitative methodologies (Moore, Tapper, \& Murphy, 2007). Other dimensions are also considered, such as the relevance of social class (Hupkens, Knibbe, Van Otterloo, \& Drop, 1998), maternal anxiety (Mitchell, Brennan, Hayes, \& Miles, 2009) and the impact of mothers' own eating issues on their child's feeding practices (Cooper, Whelan, Woolgar, Morrell, \& Murray, 2004; Stein, Woolley, \& McPherson, 1999).

While the majority of research on parenting feeding styles relies on self-report questionnaires after the event, there has been limited research in this domain that analyses family mealtimes in situ (Hays, Power, \& Olvera, 2001; Koivisto, Fellenius, \& Sjoden, 1994). For instance, Orrell-Valente et al. (2007) conducted observations of 142 family mealtimes, coding parental strategies such as 'neutral prompts', offers of food rewards and threats. The focus was on separating out these strategies and their impact on the child's actual consumption. While that research provides helpful lists of mealtime methods that routinely occur within families, it misses the lived work of how these are produced and recognised by parents and children (cf. Ogden et al., 2006). It also potentially obscures the interplay between 'mental' categories and embodied courses of action. For instance, research on the socialisation of children with Downs' syndrome has shown how parents use 'inner state' words (referring to affect, cognition or physiology, including hunger) to help teach children about their bodies (Tingley, Gleason, \& Hooshyar, 1994).

A separate, if overlapping, area of research within the psychology of eating literature focuses on children themselves. Such work includes the work of Birch on learning and peer modelling, and highlights the importance of the eating environment and the social nature of food, in which children are heavily influenced by their peers and those around them, as well as through learning by experience (Birch, 1980, 1990). For example, recent research suggests that if parents or caregivers pressure their children to eat more food, then children are conversely likely to eat less (Galloway, Fiorito, Francis, \& Birch, 2006). This particular study, however, examined children's behaviour in an experimental situation at school, rather than examining the complexity of everyday eating practices within the home (cf. psycho-physiological research on satiety, discussed earlier). A similar style of work has been taken up by the Bangor Food Research Unit, who have used behaviourist principles to develop a healthy eating school-based intervention programme (www.fooddudes.co.uk) that has to date been successfully implemented in the UK and overseas (Tapper, Horne, \& Lowe, 2003).

The emphasis in this literature at times appears to be on problematic issues around children's feeding, whether this be neophobia or food aversions (Cashdan, 1998; Koivisto \& Sjoden, 1996; Loewen \& Pliner, 2000) or more persistent, individual feeding 'problems' (Blissett \& Harris, 2002; Sanders, Patel, LeGrice, \& Shepherd, 1993). In accordance with the literature on parental styles, there is also a concern about who has control over (or perceived control over) children's food (Robinson, 2000; Ross, 1995). We might conclude from this work on parenting styles or the influences on children's feeding that these two areas are mutually exclusive, since there is little attempt to examine the ways in which parents and children interact collaboratively during mealtimes. Similarly, the focus on issues such as control and problematic eating might presuppose (or overlook) the kinds of activities that are carried out within a family mealtime.

\section{Sociology: Women and families}

In the social sciences more generally, the family meal remains a central feature of both the reproduction of the family as a social unit and, of relevance to us here, the daily satisfaction (or not) of our appetites. Much work in the 1980s and 1990s illustrated the connections between motherhood, femininity and control over food (Charles \& Kerr, 1988; De Vault, 1991; Lupton, 1996; Murcott, 1982). Both the quantity and the quality of food we eat as children is, from this perspective, bound up with family norms and cultural expectations. Gender in this research context is a central concern, with women often caught in a struggle over the moral and social adequacy of their feeding practices (Murphy, 2003). This area of primarily sociological work has resonances with psychological work on parental feeding practices, in which the focus is on the mother and her role in the family unit. ${ }^{1}$

\footnotetext{
${ }^{1}$ Though an early study (Jewett \& Clark, 1979), concerned more with how to involve children more productively in family mealtimes, proposed a training programme whereby children could be taught how to participate more 'appropriately' in the interaction.
} 
Other sociological and anthropological work considers the structural features of a meal (Douglas, 1972; Douglas \& Nicod, 1974), and the importance of these for creating social boundaries (e.g. what is appropriate for close family members would not be for acquaintances or strangers). Further debates in this area argue for a consideration of the meal-as-event, rather than the meal-as-object (Bisogni et al., 2007; Jastran, Bisogni, Sobal, Blake, \& Devine, 2009; Makela, 1991; Visser, 1993). Meals might then be seen as mediators that enable socialisation into what it is to eat, and to be human (Otnes, 1991). With this mediating function, meals also incorporate an element of power: to feed (oneself or others) or not to feed.

The notion of power and control around mealtimes is thus a recurring theme, yet we have little understanding of how these issues play out in real time. How is power defined and exerted within mealtime interaction? In a rare study to address this issue, Grieshaber collected a corpus of case-study data from four families in Australia (Grieshaber, 1997). Each family was videoed on ten occasions, capturing daily family routines as well as meal preparation and consumption. Grieshaber then used Foucauldian discourse analysis to examine the processes of resistance and power relations between the parents and children; negotiation over food rules was treated as a means for establishing domestic order and through which the 'daily rituals of family living are socially constructed' (Grieshaber, 1997, p. 665).

Childhood problems that include and extend beyond diet have been both linked and studied through the family meal. This has lead to an interest with the routine organisation of the family mealtime. For Fiese et al., excessively rigid and prescribed routines for meals are as damaging for children's mental health as chaotic mealtimes (Fiese, Foley, \& Spagnola, 2006). Pursuing the potential causes of childhood obesity, on the basis of focus groups and a small sample of in-depth interviews, Kime (2008) argued that less ordered mealtimes were associated with obesity in children. Children eating at varying times, usually eating snacks and in varying places within the house, were at greater risk of obesity. As part of a larger study on the socialisation of food practices in children, Paugh and Izquierdo examined the negotiation of types of food between parents and children (Paugh \& Izquierdo, 2009). Rather than necessarily modelling healthy eating practices, they found that adults were more likely to model negotiation skills. This adds further evidence to suggest that mealtimes are a site for learning not only about eating but also about the social practices which constitute eating.

Despite some debate as to whether family mealtimes are in decline or not (Murcott, 1997), we still know very little about the actualities of eating together as a family. More recent work begins to make visible the social and cultural elements of satiety (Kristensen, Holm, Raben, \& Astrup, 2002) bringing out its more than physiological nature. Though here again, what is missing is an understanding of how such elements are drawn upon, oriented to, ignored, etc. in the lively interplay of families eating around tables and/or in front of televisions. The sociological and anthropological work noted above provides a clear overview of domestic practices around families and eating, but little if any of this pursues the mealtime for, and in and of, itself.

\section{Mealtime interaction}

While a characteristic of much of the work on food and eating is that it neglects to examine mealtimes themselves, a converse pattern shows that much of the work on mealtimes does not explicitly focus on the food or eating practices therein (Aukrust \& Snow, 1998; Pan, Perlmann, \& Snow, 1999; Vuchinich, 1990). In the final part of our extended literature review, we consider the range of work on mealtime interaction, including research using conversation analysis, sociolinguistics and ethnography.
Conversation analysis has the family meal as a fruitful source of data for its studies of a number of other family activities that occur at the dinner table. Some examples are: the emergence of selfrepair in children (Forrester, 2008), the request for and providing of moral accounts as definitional and binding (Sterponi, 2003), contractions in repair (Schegloff, 2004), exploring new domains of knowledge (Goodwin, 2007b) parental directives (Goodwin, 1996) and planning next activities (Wingard, 2007). Indeed, one dinner conversation was analysed by Sacks (1992) during his 'Lectures' in terms of its sound environments and the transformation of offers into requests.

In sociolinguistic and intercultural pragmatic research, while there is a closer focus on the meal as event, it is in terms of how it constitutes broader cultural issues. With a more specific focus on the dynamics around the dinner table and the processes of socialisation for example, Ochs and Shohet place mealtimes at the centre of any cultures' settings for socialising individuals into becoming 'competent and appropriate members of a society' (Ochs \& Shohet, 2006, p. 35). Not only do members of any society find sustenance in the form of food, they also find sustenance in abiding familial relationships. Meals are thus occasions that both preserve and transform social organisation: of the meal, the family and the family's location in culture (Ochs, Pontecorvo, \& Fasulo, 1996).

In the West, Blum-Kulka's much cited work argued that we can place family meal conversations in three broad areas of importance for the family and children (Blum-Kulka, 1997). First, the dinner is an 'intergenerational social event' (Blum-Kulka, 1994, p. 45) where children acquire competence from their siblings, parents and other relatives in dealing with multi-party conversations where age, generation and levels of intimacy matter. Second, they learn simultaneously how to participate in and structure dialogue with others and third, they venture forth into the hazards of 'monologic discourse' (Blum-Kulka, 1994, p. 45) for the first time. BlumKulka's work has been taken up elsewhere to show how at different developmental levels children are both taught to argue and adapt those arguments to the situation within which they occur, not least in that they are around serving, eating, rejecting and finishing food (Brumark, 2008) or food's part in accepting new members into a family (Dedaic, 2001). In the broadest possible sense, Blum-Kulka and others (Pontecorvo \& Fasulo, 1999) remind us that the dinner is also where children meet wider cultures and find their families and their part in those cultures.

Of pertinence, Blum-Kulka purposefully removed the instrumental talk of families bound up with:

excluded from this analysis are turns focused on instrumental dinner talk (e.g., "pass the salt, please"), such talk being considered by definition "nontopical" and hence subject to a different set of discourse norms for those operating for topical talk. (Blum-Kulka, 1994, p. 9)

Where Blum-Kulka's seminal study excluded the instrumental aspects of mealtimes, in this article we intend to return to those features which are bound up with serving, eating, shifting between courses and finishing the meal. Blum-Kulka excluded them on the basis of their non-topicality. Where our interests are in appetite and satiety, then it makes sense to reverse Blum-Kulka's formula and focus on those sections of family talk that are intertwined with the organisation of eating together.

Ochs et al.'s (1996) groundbreaking study of the socialisation of taste showed that children, in parallel with learning the nutritional and material values of food, were tutored in the functions of food as reward and as a central pleasure in our lives. Before we begin to assume, however, that children are the passive recipients of cultures of eating, Ochs and Shohet argue that mealtimes are not simply sites for transmission of self-explicating rules, norms or 
attitudes. They argue instead that children constantly remake and refashion their tastes in 'socially and experientially asymmetrical relationships' (Ochs \& Shohet, 2006, p. 35). Children, though not having all the knowledge of eating together that their parents have to draw on, are busy acquiring eating-cultures and remaking them as their own.

In our earlier research we have examined how colleagues' coffee breaks are ended through the intertwined courses of drinks completion and conversational topic completion (Laurier, 2008). To avoid abrupt departures with socially damaging consequences, people initiate their closing 'goodbyes' with 'pre-closings' such as 'we-ell', 'o-kay' and 'so-oo' (Schegloff \& Sacks, 1973). The drinking up of a cup of coffee served as a non-verbal 'pre-closing' which could be taken as such by those present (Laurier, 2008). Interestingly it could be met with drinking-up of their drink in return, showing an orientation to the finishing up of the drinks as much as the completion of any topic of their conversation during their time together over coffee. With a focus on feeding families, we have also examined how food appreciation and pleasure is constructed (Wiggins, 2002), how healthy eating advice is ordered (Wiggins, 2004a), and how assessments of food are produced (Wiggins \& Potter, 2003) and challenged (Wiggins, 2004b) in everyday family mealtimes. We have also begun to examine the processes through which having 'enough' food is negotiated (Wiggins \& Hepburn, 2007). Related work by Mondada complements this research and details how conversation analysis can be used to examine the organisation of food assessments in family meals (Mondada, 2009).

From this earlier research, we have developed an approach to eating and drinking that foregrounds their roles as resources in sequential courses of joint action. This approach, informed by conversation analysis, neatly dissolves the boundaries between psychological and sociological research, providing a means through which the social organisation of appetite and 'fullness' can be more closely examined. Parents and children employ subtle variations in expressions of not 'wanting' or 'needing' more food which are consequent upon the nuances of how they are offered, asked, queried, pestered or told to eat more (Craven, 2009; Jenkins, 2009). Ownership of physiological states - and who has the right to 'know' whether a child is full or not - is a complex and delicate matter. Conclusions are difficult at this early stage, though so far we can at least begin to see that such matters are inextricably bound up with the sequential concerns of the mealtime.

\section{Method}

The data corpus consists of approximately $90 \mathrm{~h}$ of audio-taped family mealtime conversations (collected by SW) and an additional $8 \mathrm{~h}$ of video-taped family mealtimes (collected by EL). The entire corpus was searched and indexed for the 'endings' of either particular food items, courses or the meal as an event. Over 150 pages of transcript were thus extracted from the full corpus, enabling a closer examination of particular features of meal/food endings. The extract file was transcribed using Jeffersonian conventions, which provide for a focus on turn-taking, pauses and emphases within the speech (Jefferson, 1984). To begin to hint at the remarkable variety of occasions, members and settings for mealtimes we selected three episodes with children of different ages (pre-school, primary school age and teenagers), three occasions (a barbecue, routine meal and Christmas) and families of varying sizes. Clearly there are many other possible contrasting specimens mealtimes one might select: restaurants, birthdays, single-parents, three generations, breakfasts, sandwiches, staggered meals when parents eat after children, weekdays versus weekends, and so on.

Our aim here, as noted earlier, is to offer a suggestive analysis of single instances from family mealtimes, in order to build on our literature review and to begin to point to alternative ways forward with this area of research. As detailed in our introduction, we draw upon the interdisciplinary approach of conversation analysis to provide descriptions of the sequential organisation and categorisation work that provides for the orderly (and disorderly) character of family mealtimes. An important principle of conversation analysis (and its intellectual sibling, ethnomethodology), which we can only mention in passing here, is that the analysis it aims to describe is that done by those members of society it is studying. As such, while we aim to describe, as researchers, a suggestive selection of the features of conversation and interaction at mealtimes, these are to be features that are oriented to and used by the families themselves. Given that this journal is not, of course, based in the field of conversation analysis, we will look toward introducing it as a potentially profitable approach for studies of human behaviour toward food.

\section{Results}

In this section, we provide three fragments, chosen as typical examples, through which we explore the themes of satiety, the family and mealtime organisation raised in the introduction. Each fragment will be succeeded by a preliminary examination from a conversation analytic perspective.

In this first extract, taken from the video-recorded data, we see parents Tom and Barbara encouraging their four-year-old son, Robin, to finish his meal (they are having a barbecue outside). This is rather a lengthy extract, though we include it in detail here to illustrate the progression through different stages of the meal, from 'chivvying' Robin, to negotiating dessert, to noting the consequences of unfinished food.

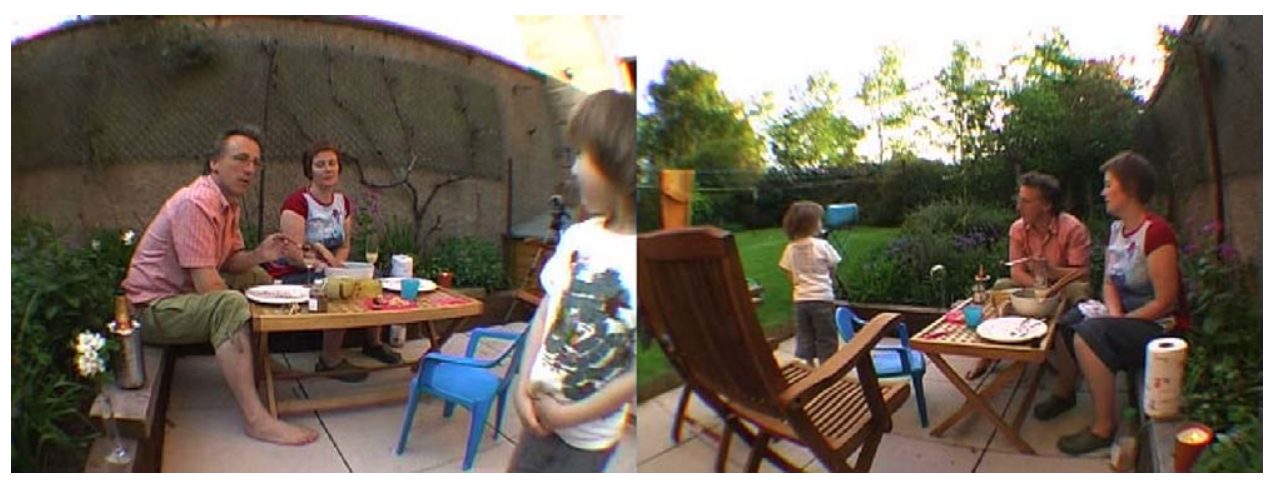



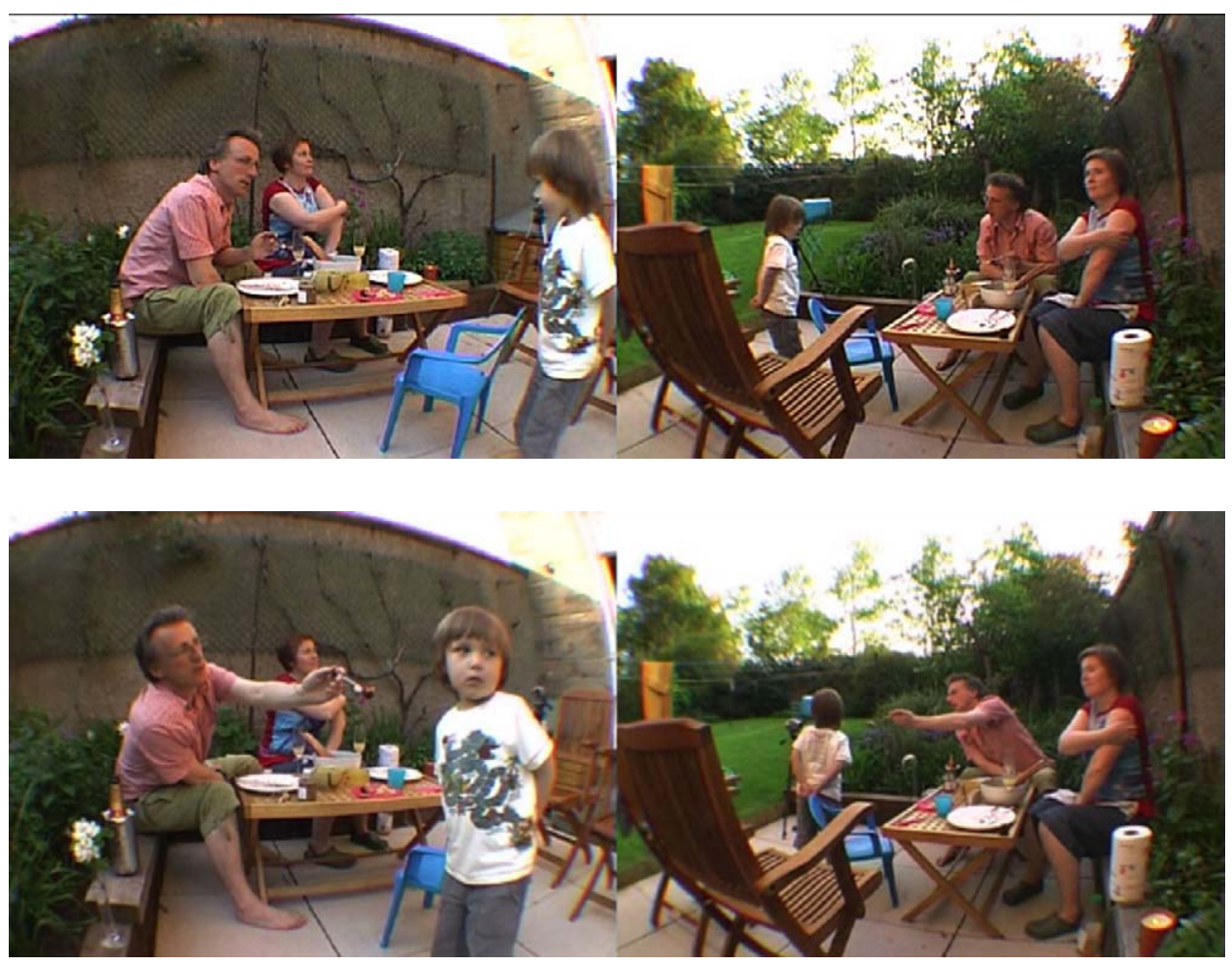

\section{Extract 1:}

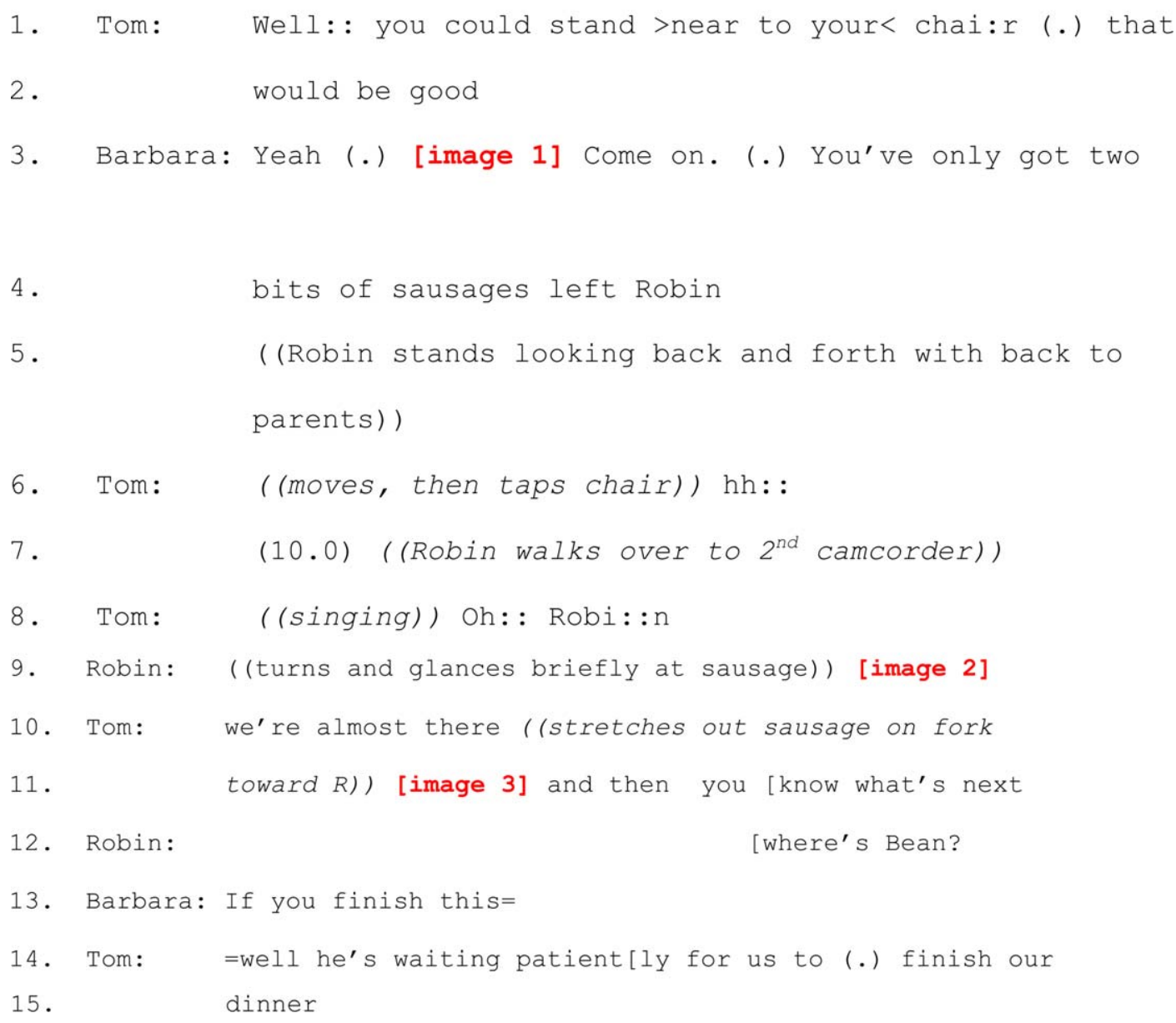




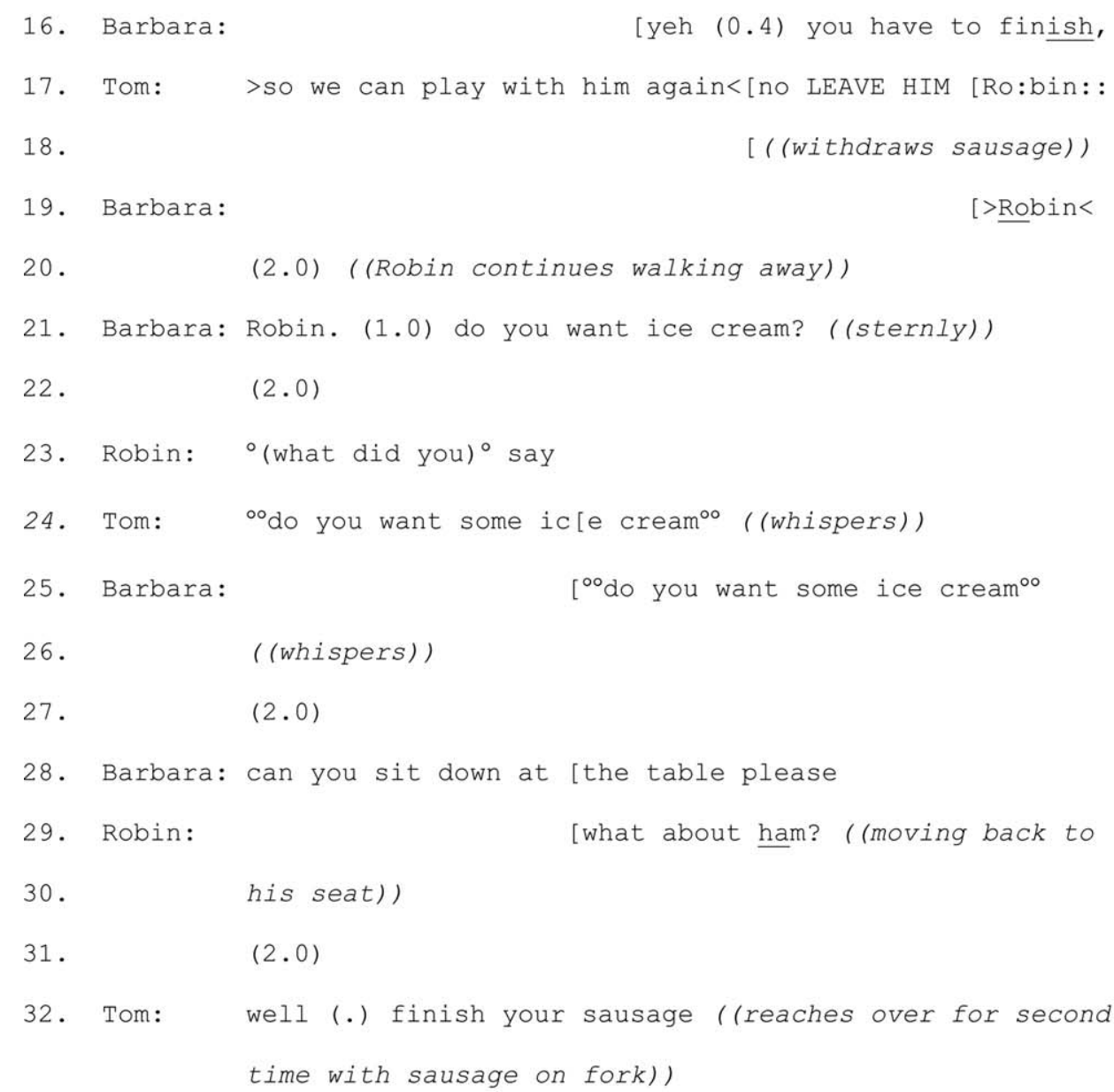

33. Barbara: without ham?

34. Tom: ${ }^{\circ}$ what about (ham) ${ }^{\circ}$

35. Barbara: 'big mouth $>$ come on $<^{\circ}((R$ closes in on fork $))$

36. Tom: (>go go<) ((R starts to bite/licks sausage))

37. (2.0) ((Tom withdraws fork as $R$ walks away))

38. Tom: are you finished then Rob?

39.

$(1.0)$

40. Tom: are you finished? (( $R$ walks further away))

41. Robin: ${ }^{\circ}$ yes ${ }^{\circ \circ}$

42. Tom: I can't hea: :r you (.) can you turn round

43. Robin: I'm finished

44. Tom: all right. (.) do you want ice cream (.) strawberries

45. Tom: yes

46. Tom: 'kay ((pulls sausage off fork onto $R^{\prime} s$ plate))

47. (7.0) ((R returns to table $))$ 
We initially characterised this data fragment as an instance of parents chivvying a young child, where 'chivvy' would be trying to push on or hasten the completion of the main course, though at the same time carries overtones of nagging. Nursery-aged children may commonly dawdle over their food, stopping as the child does here, to walk around, or play with their cutlery, plates and food. The data fragment also forms a stimulating comparison with the older families we will examine in a moment. For the older families, children have acquired various rights, procedural capabilities, and perhaps, above all, competence in a 'culture of eating' (Ochs \& Shohet, 2006). Here by contrast we have a young child who still has much to learn about how the meal as a family event works.

The episode begins with the father, sausage raised, requesting that Robin return to his chair. It is notable throughout this data fragment, and the majority of our other data from this family, that the father is central to the organisation of the family meal, a pattern that is at odds with much of the sociological and psychological work on the family cited in our in introduction (e.g. De Vault, 1991). A recurrent mealtime tactic that is evident in the sausage's role in this fragment is that the father switches from waiting for his son to finish, to feeding him in order to both increase the pace and accomplish the completion of meals. While switching to feeding the child may often succeed, in this meal it does not, marking out in an obvious way how children are not simply passive recipients of rules around dining together (Ochs \& Shohet, 2006). Nevertheless, and we will describe below, we still have a strong sense of how the food itself has an interactional role in the pursuit of smaller and larger courses of action such as completion of conversational turns and completion of courses (Laurier, 2008).

In the fragment, at line 3 , we have the beginnings of the pursuit of completion and compliance by the mother 'Come on. You've only got two bits of sausage left.'; the sense of pace being made available in 'come on', hearable as hurrying Robin. The second part of pursuing compliance providing, firstly, a minimisation - 'only' - of the task that remains and, secondly, the units - 'two bits' - that will make the course complete. The mother is further configuring how the remaining food should be perceived by the child. There is no response from the son who continues to stand looking to and fro, with his back to his parents (line 5). Having tapped the chair and sung his son's name the father seeing his son turn toward him (Image 3; lines 6-11) in a remarkably closely timed movement, offers the bit of sausage. As quickly as the father moves, the son also swings his head away out of line and thereby declining the offer (line 9). Again for children of this age and younger, food is commonly declined by turning their faces away from morsels offered on spoons or forks. At line 10, the father's 'we're almost there' builds on the mother's pursuit of compliance through minimisation, shifting though to the end rather than the means, he continues also to hold the sausage out, offering it to his son (lines 10 and 11). What is as striking (as it is routine for children of this age) is a lack of compliance to the requests from his parents.

Here we also see the switch from what we might take as parental attempts to hurry the child (by making them aware that there is only a small amount of food to be eaten and thus staying on the subject of this course) to a further routine method of accomplishing main course completion by mentioning pudding (the uses of pudding as reward for the labour of the main course are an Anglo-American convention (Bourcier et al., 2003; Ochs et al., 1996; Ochs \& Shohet, 2006)). In this case it first appears in a question format - 'and then you know what's next' - where the child's attention to the meal is not gained. In fact this question meets another question of his which makes recognisable what he would like to do next: play with the dog. The father uses the question about the dog to, once again, try and bring his son's attention to the completion of the meal (lines 14 and 15). The dog's status is formulated as 'waiting patiently for us to finish dinner', and thereby aligned with the parent's concerns around the completion and the length of the meal.

Mention of pudding is a risky business since with small children it may lead to the abandonment of the main course. In terms of the course of a family meal it may not be resorted to as a bribe until the near completion of a main course. If the 'sweet' is mentioned too early, then the young child may refuse their current food in favour of ice cream, fromage frais, chocolate, etc. In extract 1 , as their son begins to walk away, the mother asks in a surprisingly stern tone whether he wants ice cream (lines 20 and 21 ). The use of tone indicates once again other analysable aspects of what is going on, not least of which affect in the lingering irritation being displayed by the mother (Goodwin, 2007a). There is perhaps also hearable a threat in this, the offer being made in an irritated tone allows us to hear it as an offer that might be removed and sequentially that we would expect there is some further request (demand) to follow.

Having brought up 'ham' as an unlikely request for pudding (line 29), the son finds himself facing a condition. This condition is nicely produced in that the father also brings the sausage to his son which, as we have already noted, often leads to the son accepting the food and eating it. In this case he merely nibbles and, like the fish that refuses the fly, escapes again. His abandoned nibble finally brings a 'completion check' from his father ('are you finished', lines 38 and 40). A completion check that also has to be pursued twice as it receives no response. What we have seen in our data on this family and other data on children of this age is the considerable labours of parents to secure what we term 'completion statements' (e.g. 'I've finished'). This might seem straightforward, yet the problem is that whenever there is food left (or "drinks to be drunk" (Laurier, 2008, p. 175) then the mealtime can potentially continue. With our first extract what we begin to see in this fraught pursuit of two bits of sausage being eaten by their son (or not) is that the parents are involved in the challenges of introducing the very young to the rules surrounding eating together (Raffel, 2004).

What we want to note here, as is common from our other observations of pre-school families, is that the parents tend to avoid asking whether their children are full. When pre-school children with populated platters attempt to claim they are full by pushing away a plate, saying they are full, etc., they may be met with disbelief, encouragement, pleading and more, which speaks to their limited rights to know they are full. The absence of satiety as something pre-school children can claim in the face of a cluttered plate is interesting in that one would perhaps expect that while the social ritual associated with completing meals might be hard to learn, feeling full or not as a simple physiological state would be something small children would be able to state for the benefit of their parents. So surely parents would begin with checking on whether their children were full or not and gradually teach them the criteria for finishing courses and finishing meals over all. Hopefully the data above begins to reveal that the fullness of small stomachs is judged through portions and their consumption.

In the next, rather shorter extract, we consider how the psychological notion of 'sensory-specific satiety' might work in practice. This extract is taken from near the end of an audiorecorded family meal, with Lesley the mother and Ben, her 14year-old son. This extract was also analysed in an earlier paper, though here the focus is on finishing and moving on in the meal rather than fullness per se (Wiggins \& Hepburn, 2007). There are two other younger children and a father in this family, though they are not audible in this segment of talk. 


\section{Extract 2:}

\begin{tabular}{|c|c|c|}
\hline 1 . & Ben: & it's not something that'll stick like 'Byker Grove' \\
\hline 2 . & Lesley: & no $[$ it's not $(---)$ \\
\hline 3 . & Ben : & [or Grange Hill \\
\hline 4 . & Lesley: & >do you want anything $\uparrow$ else or have you had enough $<$ \\
\hline 5 . & Ben: & 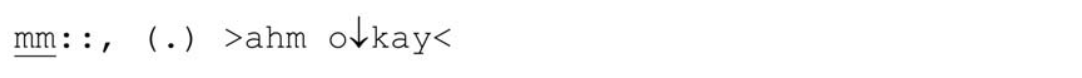 \\
\hline 6. & & $(1.0)$ \\
\hline 7 . & Lesley: & you: (.) >don' want $<{ }^{\circ}$ cake then.$^{\circ}$ \\
\hline 8 . & & $(1.0)$ \\
\hline 9 . & Ben: & ohh: (0.2) that's different (0.2) (alrí' then) \\
\hline 10. & & $(1.2)$ \\
\hline 11. & Ben: & are these little cakes: 'or ${ }^{\circ}$ whate:ver \\
\hline 12. & & $(0.4)$ \\
\hline 13. & Lesley: & well there's: (0.2) a var个iety of ${ }^{\circ}$ things ${ }^{\circ}$ \\
\hline 14. & Ben: & ${ }^{\circ} \mathrm{Can}::$ (.) you show them to me please ${ }^{\circ}$ \\
\hline 15 . & & $(3.2)$ \\
\hline
\end{tabular}

The section we are particularly interested in here is that between lines 4 and 12; as it is during this period that there is a shift from topic talk (a television programme in lines $1-3$, and something written on Ben's hand, following line 15) to the instrumental talk of the meal, cf. (Blum-Kulka, 1994). This takes place over just around $20 \mathrm{~s}$, yet it marks a subtle negotiation of both taste (wanting something, cake as 'different') and fullness (having 'enough). Let us focus on the issue of finishing the meal for the purposes of this paper.

In noting Lesley's seemingly abrupt topic change in line 4, we can already begin to see a sharp contrast with the first extract which contained no 'satiety checks' ('are you full'; instead, 'completion checks') - in that here we have a mother directly asking her teenage son whether he has 'had enough' (line 4). This marks a potential emerging difference between younger and older children and their treatment as competent and aware in eating food. That is, in mealtimes involving younger children we see less evidence of 'fullness' being checked than we do with older children (as with Ben in the extract above). Furthermore, in extract 2 there are no directives used upon the son (cf. 'finish your sausage', extract 1 ). The structure of the talk is fairly simple (e.g. adjacency pairs of question and answer) with no repetition or inclusion of different topics (such as Robin's inclusion of the ham, in extract 1). One thing we might then pick up on, is the way in which different conversational practices are more or less common at different stages of children's development (Forrester \& Cherington, 2009; Ochs et al., 1996; Wootton, 1997). This is something that the earlier noted sociological work might be hinting at, but never really explicates in practice.

Developing this issue a little further, we might consider the work of Ben's turn in line 5: 'mm:: (.) ahm okay'. The elongated 'mm::' suggests a reflective tone; this is something that Ben appears to be considering before providing the next part of his response ('I'm okay'). While this is not directly challenged (cf. Wiggins, 2004b and below) and odd that it would be, nor is it treated as the final word on this subject. Ben's knowledge of his own appetite is tempered by that of his mother: she guides the interaction by encouraging, it might be argued, further temptation. The exchange between mother and son is more subtle than the lengthy exchange of turns in extract 1 , and is, of course, a consequence of Ben having already being socialised into the operations of mealtimes and taste (Ochs et al., 1996).

Moving now to focus on how the family members attend to fullness, we can first note how Lesley wraps two questions together to elicit Ben's response: (1) do you want anything else, and (2) have you had enough. Such double-barrelled questioning produces ambiguities in responses without clarificatory work by the respondent since to be correct he would have to answer yes to one and no the other question. What it achieves sequentially is not so much one or the other; it is to produce first an offer, and then a 
satiety check. In other extracts within our data corpus, we have examples of this in the alternate order (satiety check, then offer). In the order displayed in extract 2 above with its ambiguity it is handled by Ben with 'okay' which is an adequate response to 'anything else/had enough'. This question and answer sequence could be analysed further but for our purposes here it serves to point to an emerging phenomenon of satiety checks in family mealtime discourse.

What happens next is that, following Ben's satiety statement, Lesley then presents a further, indirect offer of cake as dessert. Note, again, how this is phrased: 'you don't want cake then' is dealt with in 'if-then' terms, Lesley providing an upshot of Ben's measured satisfaction on line 2. One possibility is that she is using this uptake of his remark as the opportunity for a server's tease. The mother as server appears to know, both that there is a sweettreat to follow and that her son may want it. After a pause, Ben then responds in a way that allows him to contradict his earlier state of being 'okay' (on line 5, with 'that's different') and thus hesitatingly accepts his mother's offer. At this point, however, there is still some negotiating to be done, and a straight-forward acceptance of the cake is not produced.

On one level, what appears to be going on is both the construction and management of sensory-specific satiety (cf. psychological research noted in the introduction) in action. The inclusion of 'then' in Lesley's turn on line 3 opens up the possibility that one might have 'had enough' (i.e. be sated) of one food, while still 'wanting' (i.e. desiring) another, possibly sweeter food. That is, Ben's affirmation that he has had enough is not treated as being the end of the story; there is no progression to closure for Ben and his meal, and indeed the conversation following this extract shifts to other topics, as Schegloff and Sacks (1973) would suggest, and to the discussion, in turn, of what the other children are eating.

The notion of sensory-specific satiety is thus constructed playfully through Lesley's ushering in of cake, and subsequently managed through Ben's following turns in the interaction. While the mention of cake may mean that options change ('that's different', line 5 ), there are other factors to consider: the size of the cake/s ('little cakes', line 6) and their appearance (line 8). In just this brief snapshot within a mealtime, then, we can begin to see how psychological notions of appetite and satiety begin to play out alongside familial relations and interactional processes during mealtimes. To fully understand the impact of sensory-specific satiety, for example, on people's eating practices, we really need to examine how such processes are invoked, organised and negotiated in mealtime settings.

In the final extract, we see Lynn managing the quantities and qualities of foods eaten by her sons, thirteen-year-old Adam and nine-year-old Nicholas, and her four-year-old daughter, Daisy. This mealtime was recorded soon after Christmas, so there is mention of a Christmas cake (a rich fruit cake, covered with marzipan and icing) which becomes the focus of the discussion early on.

\section{Extract 3:}

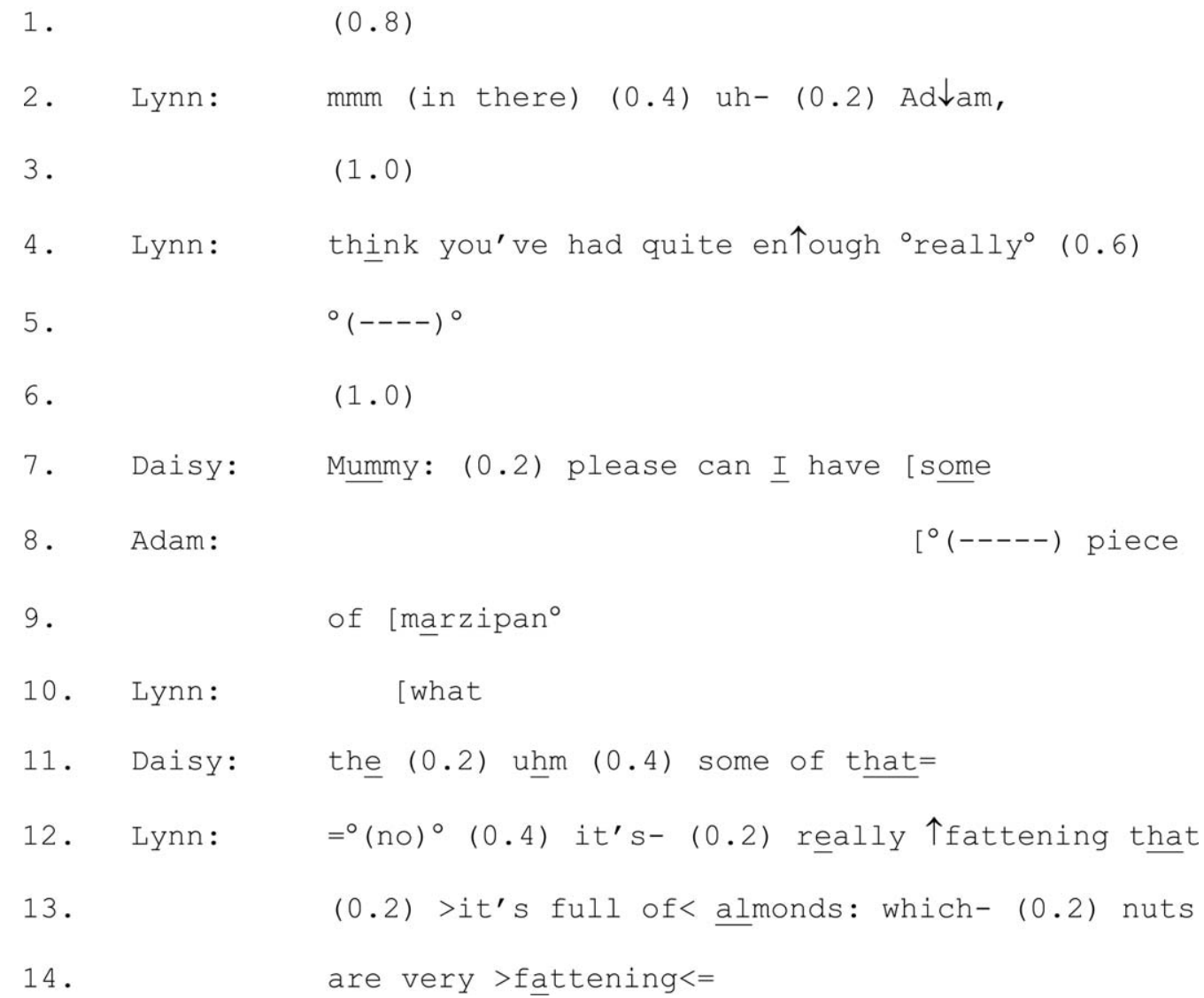




\begin{tabular}{|c|c|c|}
\hline 15 . & Adam: & $=$ what \\
\hline 16. & & $(0.8)$ \\
\hline 17. & Lynn: & marzi $\underline{\text { ppan }}$ \\
\hline 18. & & $(1.4)$ \\
\hline 19. & Lynn: & and you've got the corner (.) so you [had more \\
\hline 20 . & Nicholas: & [can I have \\
\hline 21. & & 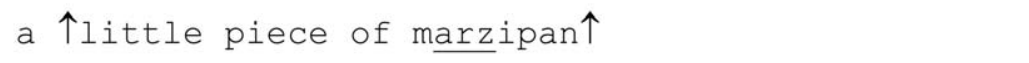 \\
\hline 22 . & & $(0.4)$ \\
\hline 23. & Lynn: & ${ }^{\circ}$ well, $\left[(--)^{\circ}\right.$ \\
\hline 24. & Nicholas: & [个please: : litt $[\underline{\text { le }}(0.2)$ very very $\downarrow$ little \\
\hline 25 . & Lynn: & [you can have some cake \\
\hline & & ${ }^{\circ}$ though ${ }^{\circ}$ \\
\hline
\end{tabular}

Unlike much of the literature on family feeding practices, the mother here appears to be attempting to restrict (rather than increase) her son's food intake (line 4). Reference is made to the 'fattening' nature of the food, hence the appeal is to health concerns (see lines 12-17) as the reason for why the food should be restricted. There are other differences between this extract and the previous two: here, there are no satiety checks or completion checks. We also have a range of ages of children present, from the pre-school child (as with extract 1 ) to the young teenager (as with extract 2). The father is also present at this mealtime, though we do not hear him in this extract; this may be a particularly pertinent example of where one parent (in this case, the mother) appears to be managing all three children and their food intakes at once.

Focusing more closely on the extract, in line 4 we have what appears to be a particular 'parenting strategy' to limit a son's food intake. In line with the observational and psychological studies examined earlier, we might then code this phrase and track the impact on the son's subsequent consumption (Orrell-Valente et al., 2007). What we find, however, is that it is more complex than this in practice. We can note, first, how Lynn's reprimand is softened ('think you've had enough really'); it is then mitigated with an explanation (lines 12-17) as if her intervention needed qualifying and supporting. Furthermore, it is not treated as the final word by Lynn's other son, Nicholas, who then requests more of the same food (lines 20-21 and 24). In this series of turns, the amounts are reduced each time, from 'little piece' to 'very very little'; later though not seen here, to 'crumbs'). What is interesting about this is that it to some extent mirrors the kinds of patterns of progressively smaller units seen in parental talk around food (i.e. encouraging children to 'eat their food', to eating 'two bits' to 'just a mouthful'). However, one is embedded in the unfolding of parental persuasion and the other, children's pleading. Also as Ochs et al. remind us the parental persuasion is occurring to attempt to finish the nutritious main course, while the children's pleading is embedded within the 'reward' of the marzipan of the Christmas cake.
To understand this extract fully, then, we need to consider the different activities going on: managing the pleas from all three children, justifying refusals on the basis of the nutritional qualities of food, drawing on the 'rules' of the table to defuse escalating pleading and the accomplishment of equity between family members (e.g. ensuring everyone has a chance to have some marzipan on their cake, line 19). Similarly, the rules of the table (Grieshaber, 1997) might be understand in a temporal framework, through which there is room for negotiation, reformulation of the rules and resistance at different stages of the meal.

\section{Discussion}

The examination of family mealtimes traverses psychological, sociological and interactional research, though to date these strands have remained separate and limited in their scope. We still know very little about how families eat together, in all their intimate yet intricate detail. The work involved in bringing family courses and meals to a close, and ascertaining the fullness of children and partners, is even more rarely examined. Our review of the literature here, and our subsequent illustration of how such issues might be explored within recordings of family mealtimes, suggest that there is ample room for a more nuanced understanding of appetite that takes into account the structures of conversation and the interactional realisation of food, discourse and appetites. Drawing on conversation analytic (CA) principles, we have the sketched out the means through which such analyses could be taken further. The analysis in this paper merely provides signposts toward an approach rather than a thorough and deep analysis of the excerpts in order to encourage engagement with this journal's interdisciplinary readership and to allow for more space to detail the theoretical overview of the field.

Common to the three extracts used was the transition between main course and pudding. Contrary to much sociological and psychological theorisation and modelling of eating, our aim was 
not to divide by social or cognitive type but rather to show how, across a deliberately juxtaposed set of families and meals, those present accomplished enforcing and following rules, or indeed, constituted 'cultures of eating', surrounding finishing a course and moving on to the next part of the meal. As such we hope to have revealed overlooked yet conventional resources while, at the same time, showing how they are put to use in the face of numerous contingencies. Clearly there were also ways in which the mealtimes departed from one another. For the preschool family (extract 1), rather than ask their child whether he was full, they pursued a more simple and mutually visible state which is to clear the plate and at the same time bring him into expressing his physiology as an inter-subjective and accountable matter rather than a private sensation. Rather than coming out of a match between physiology and eating, satiety is already underway as a social and material matter. For instance, through routinely feeding their children, parents have a sense of how much they eat and tailor their portion sizes accordingly (De Vault, 1991). To fail to finish the portion is thus to find oneself being interrogated, persuaded and worried about. In terms of their gradual acquisition of competence in language (Forrester \& Cherington, 2009; Wootton, 1997), toddlers and pre-schoolers do not yet know quite how to use 'I'm full'; they are only still learning how to properly express their pain and physiological sufferings through 'I have a headache', 'my finger is sore' and so on (Jenkins, 2009). From our description of the older families, the physiological claims of being full (or not) are used for more than physiological purposes and are equally as open to persuasion, acceptance and dispute by other family members, if in more subtle and complicated interactions. Ones which make apparent children's steady acquisition, not only of knowledge about cultures of eating, but also their increasing rights to say whether they feel full or not and whether they are finished or not.

Alongside offering these preliminary analyses of, and reflections on, course and meal completions, this paper might therefore be seen as clearing a path upon which further research might be developed. At this stage, a few questions in particular are brought to light:

1. How are children at different ages and stages socialised into notions of appetite, satiety, culinary pleasure through conversationally organised mealtime matters?

2. How is our understanding of appetite, as a psychological or sociological concept, re-specified from close examination of its manifestation in family mealtimes?

3. How is the quantity and quality of food routinely negotiated, during the dinner itself, by and between parents and children?

We have called the paper finishing the family meal, though finishing is bound up with the beginnings of course. As De Vault (1991) reminded us in her classic work, there is a great deal of planning that goes into the meal. The 'mother's work' that leads into family members receiving dishes that they enjoy and are likely to finish rather than ones that they won't. As such, a research path guided by conversation analysis could easily branch out into the shopping and preparation of food and drink for the family. In their classic work in studying conversation's organisation, Schegloff and Sacks (1973) note the centrality of caller and called for closing phone conversations, for the family meal there are correlates in 'server' and 'served'. The family member or members that serve the others can close (and start) each course or the overall meal in particular ways (and do as we have seen in this paper).

\section{References}

Aukrust, V. G., \& Snow, C. E. (1998). Narratives and explanations during mealtime conversations in Norway and the U.S.. Language in Society, 27, 221-246.
Birch, L. L. (1980). Effects of peer models' food choices and eating behaviours on preschoolers' food preferences. Child Development, 51, 489-496.

Birch, L. L. (1990). The control of food intake by young children. The role of learning. In E. D. Capaldi \& T. L. Powley (Eds.), Taste, experience and feeding (pp. 116-135). Washington, DC: American Psychological Association.

Bisogni, C. A., Winter Falk, L. W., Madore, E., Blake, C. E., Jastran, M., Sobal, J., et al. (2007). Dimensions of everyday eating and drinking episodes. Appetite, 48, 218-231.

Blissett, J., \& Harris, G. (2002). A behavioural intervention in a child with feeding problems. Journal of Human Nutrition and Dietetics, 15, 255-260.

Blissett, J., \& Haycraft, E. (2008). Are parenting style and controlling feeding practices related? Appetite, 50, 477-485.

Blum-Kulka, S. (1994). The dynamics of family dinner talk. Cultural contexts for children's passages to adult discourse. Research on Language and Social Interaction, 27(1), 1-50.

Blum-Kulka, S. (1997). Dinner talk. Cultural patterns of sociability and socialization in family discourse. Mahwah, NJ: Lawrence Erlbaum.

Bourcier, E., Bowen, D. J., Meischke, H., \& Moinpour, C. (2003). Evaluation of strategies used by family food preparers to influence healthy eating. Appetite, 41, 265-272.

Brumark, A. s. (2008). "Eat your Hamburger!"-“No, I don't Want to!" argumentation and argumentative development in the context of dinner conversation in twenty Swedish families Argumentation, 22, 251-271.

Carper, J. L., Fisher, J. O., \& Birch, L. L. (2000). Young girls' emerging dietary restraint and disinhibition are related to parental control in child feeding. Appetite, 35, 121-129.

Cashdan, E. (1998). Adaptiveness of food learning and food aversions in children. Social Science Information, 37(4), 613-632.

Charles, N., \& Kerr, M. (1988). Women, food and families. Manchester: Manchester University Press.

Cooper, P. J., Whelan, E., Woolgar, M., Morrell, J., \& Murray, L. (2004). Association between childhood feeding problems and maternal eating disorder. Role of the family environment. British Journal of Psychiatry, 184, 210-215.

Craven, A. (2009). Children's responses to directives. Embodied compliance and verbal resistance. Paper presented at the Conversation Analysis and Everyday Lives, Loughborough, 2009.

De Vault, M. L. (1991). Feeding the family. The social organisation of caring as gendered work. Chicago: University of Chicago Press.

Dedaic, M. N. (2001). Stepmother as electron. Positioning the stepmother in a family dinner conversation. Journal of Socio-Linguistics, 5(3), 372-400.

Douglas, M. (1972). Deciphering a meal. Daedalus, 101, 61-81.

Douglas, M., \& Nicod, N. (1974). Taking the biscuit. The structure of british meals. New Society, 33, 744-747.

Faith, M. S., Scanlon, K. S., Birch, L. L., Francis, L. A., \& Sherry, B. (2004). Parent-child feeding strategies and their relationships to child eating and weight status. Obesity Research, 12, 1711-1722.

Farrow, C. V., Galloway, A. T., \& Fraser, K. (2009). Sibling-eating behaviours and differential child feeding practices reported by parents. Appetite, 52(2), 307-312.

Fiese, B. H., Foley, K. P., \& Spagnola, M. (2006). Routine and ritual elements in family mealtimes. Contexts for child well-being and family identity. New Directions for Child and Adolescent Development, 111, 67-89.

Forrester, M. A. (2008). The emergence of self-repair. A case study of one child during the early preschool years. Research on Language and Social Interaction, 41(1), 99-128.

Forrester, M. A., \& Cherington, S. M. (2009). The development of other-related conversational skills. A case study of conversational repair during the early years. First Language, 29(2), 166-191.

Friedman, M. I., Ulrich, P., \& Mattes, R. D. (1999). A figurative measure of subjective hunger states. Appetite, 32, 395-404.

Galloway, A. T., Fiorito, L. M., Francis, L. A., \& Birch, L. L. (2006). 'Finish your soup'. Counterproductive effects of pressuring children to eat on intake and affect. Appetite, 46, 318-323.

Goodwin, C. (2007a). Participation, stance and affect in the organization of activities. Discourse E Society, 18(1), 53-73.

Goodwin, M. H. (1996). Shifting frame. In D. S. Slobin (Ed.), Social interaction, social context, and language. Essays in honor of Susan Ervin-Tripp (pp. 71-82). Norwood, NJ: Lawrence Erlbaum Associates.

Goodwin, M. H. (2007b). Occasioned knowledge exploration in family interaction. Discourse \& Society, 18(1), 93-110.

Grieshaber, S. (1997). Mealtime rituals. Power and resistance in the construction of mealtime rules. British Journal of Sociology, 48(4), 649-666.

Hays, J., Power, T. G., \& Olvera, N. (2001). Effects of maternal socialisation strategies on children's nutrition knowledge and behaviour. Applied Developmental Psychology, 22, 421-437

Hendy, H. M., WIlliams, K. E., Camise, T. S., Eckman, N., \& Hedemann, A. (2009). The parental mealtime action scale (PMAS). Development and association with children's diet and weight. Appetite, 52(2), 328-339.

Hennessy, E., Hughes, S. O., Goldberg, J. P., Hyatt, R. R., \& Economos, C. D. (2010). Parent behavior and child weight status among a diverse group of underserved rural families. Appetite, 54, 369-377.

Hetherington, M. M. (1996). Sensory-specific satiety and its importance in meal termination. Neuroscience and Biobehavioral Reviews, 20(1), 113-117.

Hetherington, M. M. (2002). The physiological-psychological dichotomy in the study of food intake. Proceedings of the Nutrition Society, 61, 497-507.

Hetherington, M. M., Anderson, A. S., Norton, G., \& Newson, L. (2006). Situational effects in meal intake. A comparison of eating alone and eating with others. Physiology $\mathcal{E}$ Behavior, 88, 498-505.

Hetherington, M. M., Foster, R., Newman, T., Anderson, A. S., \& Norton, G. (2006). Understanding variety. Tasting different foods delays satiation. Physiology $\mathcal{E}$ Behavior, 87, 263-271. 
Hetherington, M. M., \& Rolls, B. (1996). Sensory-specific satiety. Theoretical frameworks and central characteristics. In E. D. Capaldi (Ed.), Why we eat what we eat. The psychology of eating (pp. 267-290). Washington, DC: American Psychological Association.

Hupkens, C. L. H., Knibbe, R. A., Van Otterloo, A. H., \& Drop, M. J. (1998). Class differences in the food rules mothers impose on their children. A cross-national study. Social Science and Medicine, 47(9), 1331-1339.

Jastran, M., Bisogni, C. A., Sobal, J., Blake, C. E., \& Devine, C. M. (2009). Eating routines. Embedded, value based, modifiable and reflective. Appetite, 52, 127-136.

Jefferson, G. (1984). Transcript notation. In J. M. Atkinson, J. Heritage (Eds.), Structures of social action. Studies in conversation analysis (pp. pix-xvi). Cambridge: Cambridge University Press.

Jenkins, L. (2009). 'Poor thing'. Expressions of bodily experience in family interaction. Paper presented at the Conversation Analysis and Everyday Lives.

Jewett, J., \& Clark, H. B. (1979). Teaching preschoolers to use appropriate dinnertime conversation. An analysis of generalization from school to home. Behavior Therapy, $10,589-605$.

Kime, N. (2008). Children's eating behaviours The importance of the family setting. Area, 40(3), 315-322.

Koivisto, U.-K., Fellenius, J., \& Sjoden, P.-O. (1994). Relations between parental mealtime practices and children's food intake. Appetite, 22, 245-258.

Koivisto, U.-K., \& Sjoden, P.-O. (1996). Reasons for rejection of food items in Swedish families with children aged 2-17. Appetite, 26, 89-103.

Kristensen, S. T., Holm, L., Raben, A., \& Astrup, A. (2002). Achieving 'proper' satiety in different social contexts - Qualitative interpretations from a cross-disciplinary project, sociomaet. Appetite, 39, 207-215.

Kroller, K., \& Warschburger, P. (2008). Associations between maternal feeding style and food intake of children with a higher-risk for overweight. Appetite, 51, 166-172.

Laurier, E. (2008). Drinking up endings. Conversational resources of the cafe. Language E' Communication, 28(2), 165-181.

Loewen, R., \& Pliner, P. (2000). The food situations questionnaire. A measure of children's willingness to try novel foods in stimulating and non-stimulating situations. Appetite, 35, 239-250.

Lupton, D. (1996). Food, the body and the self. London: Sage.

Makela, J. (1991). Defining a meal. In E. L. Furst, R. Prattala, M. Ekstrom, L. Holm, \& U. Kjaernes (Eds.), Palatable worlds. Sociocultural food studies (pp. 87-96). Oslo: Solum Forlag.

Mitchell, S., Brennan, L., Hayes, L., \& Miles, C. L. (2009). Maternal psychosocial predictors of controlling parental feeding styles and practices. Appetite, 53, 384-389.

Mondada, L. (2009). The methodical organisation of talking and eating. Assessments of dinner conversations. Food Quality and Preference, 20(8), 558-571.

Moore, S. N., Tapper, K., \& Murphy, S. (2007). Feeding strategies used by mothers of 3-5 year old children. Appetite, 49, 704-707.

Murcott, A. (1982). On the social significance of the 'cooked dinner' in South Wales. Social Science Information, 21(4/5), 677-696.

Murcott, A. (1997). Family meals - A thing of the past? In P. Caplan (Ed.), Food, health and identity (pp. 32-49). London: Routledge.

Murphy, E. (2003). Expertise and forms of knowledge in the government of families. Sociological Review, 51(4), 433-462.

Murray, M., \& Vickers, Z. (2009). Consumer views of hunger and fullness. A qualitative approach. Appetite, 53, 174-182.

Ochs, E., Pontecorvo, C., \& Fasulo, A. (1996). Socialising taste. Ethnos, 61(1-2), 7-46.

Ochs, E., \& Shohet, M. (2006). The cultural structuring of mealtime socialisation. New Directions for Child and Adolescent Development, 111, 35-49.

Ogden, J., Reynolds, R., \& Smith, A. (2006). Expanding the concept of parental control. A role for overt and covert control of children's snacking behaviour? Appetite, 47, $100-106$.

Orrell-Valente, J. K., Hill, L. G., Brechwald, W. A., Dodge, K. A., Pettit, G. S., \& Bates, J. E (2007). "Just three more bites". An observational analysis of parents' socialisation of children's eating at mealtime. Appetite, 48, 37-45.

Otnes, P. (1991). What do meals do? In E. L. Furst, R. Prattala, M. Ekstrom, L. Holm, \& U. Kjaernes (Eds.), Palatable worlds. Sociocultural food studies (pp. 97-108). Oslo: Solum Forlag.

Pan, B. A., Perlmann, R. Y., \& Snow, C. E. (1999). Food for thought. Dinner table as a context for observing parent-child discourse. In L. Menn \& H. Bernstein-Ratner (Eds.), Methods for studying language production (pp. 205-224). Mahwah, NJ: Lawrence Erlbaum.
Paugh, A. L., \& Izquierdo, C. (2009). Why is this a battle every night? Negotiating food and eating in American dinnertime interaction. Journal of Linguistic Anthropology, $19(2), 185-204$

Pontecorvo, C., \& Fasulo, A. (1999). Planning a typical Italian meal. A family reflection on culture. Culture \& Psychology, 5(3), 313-336.

Raben, A., Tagliabue, A., \& Astrup, A. (1995). The reproducibility of subjective appetite scores. British Journal of Nutrition, 73, 517-530.

Raffel, S. (2004). Teaching social rules. Childhood, 11(1), 117-125.

Robinson, S. (2000). Children's perceptions of who controls their food. Journal of Human Nutrition and Dietetics, 13, 163-171.

Rolls, B., Rolls, E. T., Rowe, E. A., \& Sweeney, K. (1981). Sensory specific satiety in man Physiology \& Behavior, 27, 137-142.

Ross, S. (1995). 'Do I really have to eat that?'. A qualitative study of schoolchildren's food choices and preferences. Health Education Journal, 54(3), 312-321.

Rozin, P. (1990). The importance of social factors in understanding the acquisition of food habits. In E. D. Capaldi \& T. L. Powley (Eds.), Taste, experience and feeding. Washington, DC: American Psychological Association.

Sacks, H. (1992). Lectures on conversation (Vols. I and II, pp. )). Cambridge: Blackwell Press.

Sanders, M. R., Patel, R. K., LeGrice, B., \& Shepherd, R. W. (1993). Children with persistent feeding difficulties. An observational analysis of the feeding interactions of problem and non-problem eaters. Health Psychology, 12(1), 64-73.

Schegloff, E. A. (2004). On dispensability. Research on Language and Social Interaction, 37(2), 95-149.

Schegloff, E. A., \& Sacks, H. (1973). Opening up closings*. Semiotica, 8(4), 289-327.

Sleddens, E. F. C., Kremers, S. P. J., De Vries, N. K., \& Thijs, C. (2010). Relationship between parental feeding styles and eating behaviours of Dutch children aged 6-7. Appetite, 54, 30-36.

Stein, A., Woolley, H., \& McPherson, K. (1999). Conflict between mothers with eating disorders and their infants during mealtimes. British Journal of Psychiatry, 175, 455461.

Sterponi, L. (2003). Account episodes in family discourse. The making of morality in everyday interaction. Discourse Studies, 5, 79-100.

Tapper, K., Horne, P., \& Lowe, C. F. (2003). Helping children eat fruit and vegetables. The Psychologist, 16(1), 18-21.

Tiggemann, M., \& Lowes, J. (2002). Predictors of maternal control over children's eating behaviour. Appetite, 39, 1-7.

Tingley, E. C., Gleason, J. B., \& Hooshyar, N. (1994). Mothers' lexicon of internal state words in speech to children with Down syndrome and to nonhandicapped children at mealtime. Journal of Communication Disorders, 27, 135-155.

Visser, M. (1993). The rituals of dinner. The origins, evolution, eccentricities and meaning of table manners. Harmondsworth: Penguin.

Vuchinich, S. (1990). The sequential organization of closing in verbal family conflict. In A. D. Grimshaw (Ed.), Conflict talk. Cambridge: Cambridge University Press.

Wardle, J., Sanderson, S., Guthrie, C. A., Rapoport, L., \& Plomin, R. (2002). Parenta feeding style and the inter-generational transmission of obesity risk. Obesity Research, 10(6), 453-462.

Wiggins, S. (2002). Talking with your mouth full. Gustatory mmms and the embodiment of pleasure. Research on Language and Social Interaction, 35(3), 311-336.

Wiggins, S. (2004a). Good for 'you'. Generic and individual healthy eating advice in family mealtimes. Journal of Health Psychology, 9(4), 535-548.

Wiggins, S. (2004b). Talking about taste. Using a discursive psychological approach to examine challenges to food evaluations. Appetite, 43, 29-38.

Wiggins, S., \& Hepburn, A. (2007). Food abuse. Mealtimes, helplines and 'troubled' eating. In A. Hepburn \& S. Wiggins (Eds.), Discursive research in practice. New approaches to psychology and interaction (pp. 263-280). Cambridge: Cambridge University Press.

Wiggins, S., \& Potter, J. (2003). Attitudes and evaluative practices. Category vs. item and subjective vs. objective constructions in everyday food assessments. British Journal of Social Psychology, 42, 513-531.

Wingard, L. (2007). Constructing time and prioritising activities in parent-child interaction. Discourse \& Society, 18(1), 75-91.

Wootton, A. J. (1997). Interaction and the development of mind. Cambridge: Cambridge University Press.

Zylan, K. D. (1996). Gender differences in the reasons given for meal termination. Appetite, 26, 37-44. 